\title{
Research on the Music Performance of the Sheep Horn-bell
}

\author{
Zhian Bie \\ Normal College \\ Nanyang Institute of Technology \\ Nanyang, China
}

\begin{abstract}
The Sheep Horn-bell is an old musical instrument full of local characteristics in Lingnan culture, also a typical sacrificial vessel in Bronze culture. According to current sound detection and known data report, and features that the cavity is level and there is no sound beam or grinding crack of toning file, the Sheep Horn-bell does not have the feature of double-tone bell.
\end{abstract}

Keywords-Lingnan; Sheep Horn-bell; sound detection; data; double-tone bell

\section{INTRODUCTION}

Sheep Horn-bell is a typical utensil in Lingnan bronze culture, an old national instrument full of local characteristics. According to known data, it rose during Warring States period to early Western Han Dynasty, and gradually perished in Eastern Han Dynasty. It was only discovered in southern area, and it was not seen in record of inscriptions on ancient bronzes and stone tablets in past dynasties. Researcher Jiang Tingyu, Guangxi archaeologist named it "Sheep Horn-bell" according to its form and it was accepted by the academic circle. Study and research on Sheep Horn-bell help us perceive the special object and culture of ritual and music during the period when minorities of Lingnan and southwest area marched toward kingdom culture. In this paper, the author conducts primary research on the music performance it shows according to the data of sound detection of the the unearthed objects.

\section{DATA OF SOUND DETECTION OF THE SHEEP HORN- BELL}

So far the author has mastered the data that as far as Guangxi area is concerned, ever since the 1960s, totally 24 objects have been found in scientific excavation and sporadic discovery in 11 places, which include the lost bells whose whereabouts is unknown (Pubei Lizhukui Bell, 3 unearthed, 2 lost); 23 objects have been found in 9 places in Yunnan (2 objects' whereabouts are unknown); 2 objects have been found in 2 places in Guizhou, 5 in Hu'nan (belong to collection), 1 in Guangzhou, 14 in Vietnam. Mr. Jiang Tingyu synthesizes the summary of the discovery sites and thinks that the distribution area of Sheep Horn-bell shall be.

"Red River Basin, Xijiang River Basin, Xiang River Basin, namely distributed in Yunnan, Guangxi, Guizhou, Guangdong,

Project fund: "Research on ritual and music objects and music history of ancient Ouluo nationality in Guangxi area", Key project of humanistic and social scientific research of Education Department of Guangxi Zhuang Autonomous Region. Project number: ZD2014088. south Hu'nan and north Vietnam. Their distribution seems regular, which is mostly located besides large rivers or lakes. Kunming and Jinning are besides Dian Lake; Xinping and Yuanjiang are besides Yuanjiang River(midstream of Red River); there is Panlong River in Masupo; Dama River in Xichou; Xing' an and Old Street in Vietnam are besides the Red River; Xilin and Guangnan are located in Tuoniang River and Xiyang River in the upstream of Youjiang River; in the southeast of Pubei is Nanliu River, there is Beiliu River in Rong County; there is the Pearl River in Guangzhou, and Changsha and Hengyang are accompanied by Xiang River."[1]

As 5 Sheep Horn-bells are unearthed in Hengyang, Hu'nan, Mr. Jiang adds Pearl River Basin to the original regions[2]. We have reasons to believe that with unceasing excavation of Sheep Horn-bell, there will be new changes in distributional region.

As far as the Sheep Horn-bell discovered and kept in China is concerned, there have been 19 whose sound are detected, among which 15 objects in 5 places were detected in 1980s, and 4 in one place was detected by scholars of Guangxi University for Nationalities in 2007. Next the author will state based on the research data.

\section{A. Data of Sound Detection of 6 Sheep Horn-bells Unearthed in M1, Chuxiong Wanjiaba, Yunnan}

The 6 Sheep Horn-bells unearthed in M1, Chuxiong Wanjiaba, Yunnan went through 2 sound detections in early 1980s. The first one was executed by Qin Xu and Wu Xueyuan from Yunan national music research office, and the audio tape was sent to Chinese Music Institute, Literature and Art Research Institute of Ministry of Culture for further analysis with flash frequency meter.[3] The second one was executed by scholars like $\mathrm{Wu}$ Zhao in Chinese Music Institute, Literature and Art Research Institute of Ministry of Culture with Japan's NODE TYPE: 700 flash frequency-measurement meter. The detailed data is as follow. "Table I" "Table II" 
TABLE I.

DATA 1 Of SOUNd DETECTION OF BELl IN WANJIABA

\begin{tabular}{|c|c|c|c|}
\hline No. & $\begin{array}{c}\text { Standard } \\
\text { pitch }\end{array}$ & $\begin{array}{c}\text { Middle tone } \\
\text { pitch }\end{array}$ & $\begin{array}{c}\text { Frequency } \\
(\mathbf{H z})\end{array}$ \\
\hline M1: $12-\mathrm{a}$ & 441.78 & \#A4+20 & 471.58 \\
\hline M1: $12-b$ & 441.78 & C5-4 & 552.04 \\
\hline M1: $12-c$ & 441.27 & D5+38 & 574.58 \\
\hline M1: $12-\mathrm{d}$ & 442.55 & \# D5+6 & 624.58 \\
\hline M1: $12-\mathrm{e}$ & 441.78 & $E 5-60$ & 636.80 \\
\hline M1: $12-f$ & 441.78 & $\# \mathrm{C} 6+17$ & 1056.8 \\
\hline
\end{tabular}

TABLE II. Data 1 Of SOUnd Detection of Bell In WANJiaba

\begin{tabular}{|c|l|l|l|l|l|l|}
\hline No. & 1 & 2 & 3 & 4 & 5 & 6 \\
\hline $\begin{array}{c}\text { Middle } \\
\text { tone } \\
\text { pitch }\end{array}$ & B4+23 & C5+10 & D - 35 & E5+25 & F5+40 & D6+30 \\
\hline $\begin{array}{c}\text { Side } \\
\text { tone } \\
\text { pitch }\end{array}$ & C5 - 45 & D5 - 5 & E - 50 & F5+45 & A5+3 & F6+38 \\
\hline $\begin{array}{c}\text { Interv } \\
\text { al }\end{array}$ & $\begin{array}{l}\text { Minor } \\
\text { second }\end{array}$ & $\begin{array}{l}\text { Major } \\
\text { second }\end{array}$ & $\begin{array}{l}\text { Major } \\
\text { secon } \\
\text { d }\end{array}$ & $\begin{array}{l}\text { Minor } \\
\text { second }\end{array}$ & $\begin{array}{l}\text { Major } \\
\text { third }\end{array}$ & $\begin{array}{l}\text { Minor } \\
\text { third }\end{array}$ \\
\hline
\end{tabular}

\section{B. The Data of Sound Detection of the 6 Sheep Horn-bells Collected in Pubei Museum}

Pang Zuanwu and Li Shihong from Guangxi University for Nationalities record and detect sound spectrum of the

Sheep Horn-bell Sheep Horn-bells collected in Pubei Museum (namely Pubei Dalingjiao Bell and Pubei Printing House Bell) [5], and the detailed data is as follow. "Table III"

TABLE III. Data of Sound Detection of Pubei SheEP Horn-bell

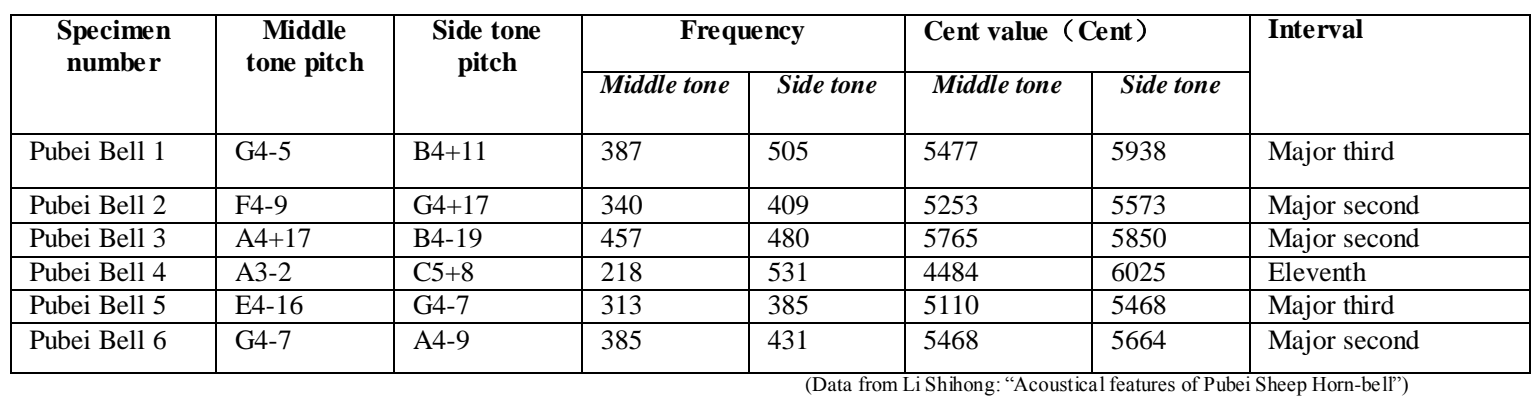

\section{The Data of Sound Detection of 4 Sheep Horn-bells in} Rong County

Yuan Hutao, 2004 graduate student of Guangxi University for Nationalities, detected the sound of the 4 Sheep Horn-bells unearthed in Rong County at the end of March, 2006, the data of which is as follow. "Table IV"

TABLE IV. DATA OF MEASUREMENT OF THE SHEEP HORN-BELl IN Rong COUNTY

\begin{tabular}{|c|c|c|c|c|c|}
\hline \multicolumn{2}{|c|}{ Specimen number } & $30-1$ & $30-2$ & $30-3$ & $30-4$ \\
\hline \multirow{2}{*}{$\begin{array}{l}\text { Middle } \\
\text { tone }\end{array}$} & Pitch & \#G4-19 & \#G4+11 & B4-4 & $\mathrm{A} 4+44$ \\
\hline & $\begin{array}{c}\mathrm{Hz} \\
\text { Frequency }\end{array}$ & 412.69 & 420.05 & 495.27 & 453.54 \\
\hline \multirow[t]{4}{*}{ Side tone } & $\begin{array}{l}\text { (cent) } \\
\text { Pitch }\end{array}$ & A4-49 & A4-40 & $\mathrm{C} 5-42$ & B4-14 \\
\hline & $\begin{array}{c}\mathrm{Hz} \\
\text { Frequency }\end{array}$ & 429.70 & 432.01 & 513.27 & 492.19 \\
\hline & Cent difference & 70 & 49 & 62 & 142 \\
\hline & Interval & Minor second & Minor second & Minor second & Major second \\
\hline Remarks & \multicolumn{5}{|c|}{$\begin{array}{l}\text { It's measured in the compiling order of Rong County Museum, Rong-Dragon No.1 in Mr. Jiang Tingyu's paper refers to } \\
\text { No.30-2 here. }\end{array}$} \\
\hline
\end{tabular}

\section{Data of Sound Detection of Shizhaishan Bell, Luobowan}

Bell and Guangzhou Bell

Scholars like Wu Zhao in China Academy of Art also detect the sound of Shizhaishan Bell, Luobowan Bell and Guangzhou Bell[7], the data of which is as follow. "Table V" 
TABLE V. DATA OF MEASUREMENT OF 4 SHEEP HoRN-BELLS

\begin{tabular}{|c|c|c|c|c|c|c|}
\hline No. & Pitch & $\begin{array}{c}(\mathrm{Hz}) \\
\text { Frequency }\end{array}$ & $\begin{array}{l}\text { Cent value } \\
\text { (Cent) }\end{array}$ & Interval & $\begin{array}{c}\text { Cent } \\
\text { difference } \\
(\text { Cent })\end{array}$ & Data source \\
\hline Shi M6-125 & $\begin{array}{l}\text { B4 }+43 \\
\text { (middle tone) } \\
\text { D5 }+32 \text { (side } \\
\text { tone) }\end{array}$ & $\begin{array}{l}506.30 \\
598.29\end{array}$ & $\begin{array}{l}5943 \\
6232\end{array}$ & $\begin{array}{l}\text { Minor } \\
\text { third }\end{array}$ & 289 & $\begin{array}{l}\text { "Primary research on law } \\
\text { trend of bells unearthed in } \\
\text { Wanjiaba and Shizhai" }\end{array}$ \\
\hline Luo M1-37 & $\begin{array}{l}\# \mathrm{C5}-27 \\
\text { (middle tone) } \\
\text { E5 - } 4 \text { (side } \\
\text { tone) }\end{array}$ & $\begin{array}{l}545.79 \\
657.73\end{array}$ & $\begin{array}{l}6073 \\
6396\end{array}$ & $\begin{array}{l}\text { Major } \\
\text { third }\end{array}$ & 323 & $\begin{array}{l}\text { "Detection of pitch of bronze } \\
\text { musical instrument of Tomb } \\
\text { M1, Luobowan, Gui County, } \\
\text { Guangxi and relevant } \\
\text { problems" }\end{array}$ \\
\hline $\begin{array}{l}\text { Guangzhou } \\
\text { Bell }\end{array}$ & $\begin{array}{l}\text { \# G4 - } 6 \\
\text { B4 - } 5\end{array}$ & & $\begin{array}{l}5594 \\
5895\end{array}$ & $\begin{array}{l}\text { Major } \\
\text { third }\end{array}$ & 301 & "Heritage in Guangzhou" \\
\hline
\end{tabular}

\section{CONCLUSION OF SOUND DETECTION OF SHEEP HORN-} BELL

In these sound detecting experiments, there are two totally different conclusions: the one is that the Sheep Horn-bell can clearly give out double tone; the other is that the Sheep Hornbell can not correctly give out double tone. At present, the educational circle mainly has the following viewpoints.

Qin $\mathrm{Xu}$ and $\mathrm{Wu}$ Xueyuan detected the sound of the Sheep Horn-bell unearthed in M1, Wanjiaba in 1980s, whose conclusion drawn according to result of sound detection is.

"The tone row of bronze drum and chime have not constituted complete five-tone scale, but there is obvious correct semitone relation (interval of minor second) in their musical scale, which can be regarded as the relation between modified fourth note and fourth note, or modified first note and first note, which contains the element of the six-tone or seventone scale, and indicates that the minority music (including instrumental music) in Yunnan 2000 years ago was not limited to simple five-tone scale."'[8]

At the same time, the two indicate in the report of sound detection: "there is double ton in Wei Bell, the pitch is similar when knocking on the parts of tunnel and drum."[9]

In 1983, scholars like Wu Zhao in Chinese Music Institute, Literature and Art Research Institute of Ministry of Culture directly detected with Japan's NODE TYPE: 700 flash frequency-measurement meter, this time they found that "the parts of tunnel and drum of the 6 chimes can give out two keynotes in different frequencies".[10] Based on the sound detection of musical instruments like bronze drum and Sheep Horn-bell, they think that.

"Early period joining the Spring-Autumn and the Warring States, there had been scale form characterized by pure third (lower third) in Erhai area represented by Xiangyun and Xiongchu; later there was scale form characterized by major third around Dianchi."

The raised the theory that "Budi tuning system" takes "A3+31 as the first tune". Scholars like Wu Zhao also detected the sound of 3 Sheep Horn-bells of Shizhaishan M6-125, Luobowan M1-137, and Guangzhou Bell, mentioning that the parts of tunnel and right drum can give out keynotes in different frequencies.[11]

Pang Cuanwu and Li Shihong of Guangxi University for Nationalities recorded and detected the sound of the 6 Sheep Horn-bells collected in Pubei Museum (namely Pubei Dalingjiao Bell and Pubei Printing House Bell), and pointed out that the tone tuning effect of Sheep Horn-bell nowhere near Zenghouyi Chime unearthed in Sui County, Hubei, whose middle tone and side tone can not well divide, the change of amplitude can not reach ideal effect, and it can't eliminate sound wave, so it can't correctly give out two tones.[10]

In March, 2006, Yuan Hutao of Guangxi University for Nationalities detected the sound of the 4 Sheep Horn-bells unearthed in Rong County, whose pitch was: \#G4-19\#G4+11 B4-4 A4+44 A4-49 A4-40 C5-42 B4-14, and he thought that: Longjinghua Bell of Rong County did not apply double-tone technology, and even the middle tone is bad. Maybe this set of bells were not truly used to play, but only used in a Buddhist or Taoist mass. [14]

\section{CONCLUSION DRAWN FROM THE DATA OF SOUND DETECTION OF THE SHEEP HORN-BELL}

There was once a discussion of whether the Sheep Hornbell is "double-tone bell". So-called double-tone bell refers to the bells which can give out two clear keynotes at the parts of middle tone and side tone, mainly in relation of major and minor third. As per the unearthing condition, before the middle of the Spring and Autumn Period, musicians generally marked the location of side tone with pattern or character, for example, there were 3 tunnels inside the wall of Yinghou Bell of Gongwang Period unearthed from Lantian, Shaanxi, the right drum part was decorated with pattern of phoenix, and the middle tone and side tone tended to have the relation of pure tune minor third interval [15]. In 1976, 21 Xing Bells were unearthed from Zhuangbai Village, Fufeng County, Shaanxi, the most of which had tunnel inside the wall and the middle and side tone decorated with patterns, and the middle and side tone tended to have relation of major and minor third harmonious interval[16]. After the middle of the Spring and Autumn Period, this marking method disappeared, but the inner tone tuning of the bells further developed. For example, 26 Wangsungao Bells in the late Spring and Autumn Period unearthed from No.2 Xichuanxia Temple, He'nan, 12 bells in 
the late Spring and Autumn Period unearthed from Caihou Tomb in Shou Xian, Anhui, and 45 bells in early Warring States period unearthed from Zenghouyi Tomb all had no pattern of phoenix on the side tone, but they had tunnel and ridge inside the wall, so their middle and side tones tended to have relation of major and minor third interval, manifesting the maturity of manufacturing of double-tone bell.

As per the existing unearthing material and the 19 Sheep Horn-bells whose sound have been detected, the earliest was Wanjiaba Sheep Horn-bell in late the Spring and Autumn Period and early Warring States Period. There is a little dispute on its performance, but as per the compilation and effect of sound detection of the 6 bells, its performance can't compare with bells of the Central Plains (which is discussed above), but it was enough to show that the technology of bronze bell was excellent for the "unsettled land" far away from the central plains at that time.

As per the data of sound detection and musical performance of the known Sheep Horn-bell, the author thinks that: from the earliest Sheep Horn-bell in Warring States period unearthed form Wanjiaba, Yunnan, to Sheep Horn-bell unearthed from Jinning, Xilin, Guangnan and Malipo, from Sheep Horn-bell unearthed in the northwest to Guigang, Guangxi and Liuzhou, Gongcheng in northeast of Guigang, and Pubei and Rong County in the south of Guigang, the musical performance of Sheep Horn-bell went downhill. There are two points which need to be stated: firstly, the sound detection shows that Wanjiaba Sheep Horn-bell had best musical performance, 6 bells in one compilation, whose bronze technology and musical performance could not compare to bells of the central plains; secondly, the musical performance of Sheep Horn-bell got worse as it went farther south.

As per the unearthed Sheep Horn-bell, there is no inscription on the bell surface or pattern or character indicating the location of side tone, there is neither trace of tone tuning or tone ridge inside, so the problem of double tone can only be judged form the quality of middle and side tone. As per the data detected by $\mathrm{Wu}$ Zhao, the pitch of Wanjiaba Bells changed with the alternate changes of bells, the interval between middle tones were mainly minor second, and the interval between middle tone and side tone were also mainly minor second. The first 5 bells presented a relation of unison connection with the adjacent middle and side tone, which was similar to the condition of the two sets of bells unearthed from sacrificial pit of the state of Zheng in Xinzheng, He'nan. There was trace of tone tuning on the chimes of Xinzheng, which were dated back to the middle of the Spring and Autumn Period, much earlier than Wanjiaba Bell. Wu Zhao and Qin Xu used a flash strobocan made in Japan, which was a sound detector specially designed for music research. The sound detector used by Wu Zhao could not directly generate visual spectrogram or show the synthesis of frequency of musical tone. There were only 3 types of data of pitch, frequency and cent in Wu Zhao's sound detection on 9 Sheep Horn-bells in 4 places, thus we could not figure out whether there was interaction effect between the two when knocking on the middle tone (or side tone). What Li Shihong used was ED1011 low-frequency spectrometer, and the data was collected and saved by computer, apart from pitch and frequency, it could also offer data of spectrogram and sound intensity, thus we could confirmed that Pubei Dalingjiao "could not correctly give out two tones". Mr. Li Chunyi held cautious attitude toward whether this set of bells applied double-tone technology in discussion on the tone row of Wanjiaba Bell, "there is great difference in the cents between the side and middle tones, and it seemed that the technology of disposing the intonation of bells was not enough in that region at that time"[20]. Thus, it can be known from the irregularity of the data of double tone and the bad tone quality that the Sheep Horn-bell was not double-tone bell.

\section{REFERENCES}

[1] Jiang Tingyu. Supplement to bronze Sheep Horn-bell [J]. Study of Nationalities in Guangxi, 1989 (4).

[2] Ditto.

[3] Yunnan Archaeological Team. Report on excavation of ancient tomb in Chuxiong Wanjiaba [J]. Acta Archaeologica Sinica, 1983 (3).

[4] Li Chunyi. Comprehensive discussion on China's unearthed musical instrument [M]. Beijing: Cultural Relics Press, 1996: 287.

[5] Pang Cuanwu, Li Shihong. Acoustical features of Pubei Sheep Hornbell [J]. Journal of Guangxi University for Nationalities, 1989 (3).

[6] Yuan Huatao. Research on several issues of Sheep Horn-bell [D].Guangxi University for Nationalities, 2007.4, 11-12.

[7] Wu Zhao, Li Kunsheng, Zhang Shiquan. Primary research on law trend of bells unearthed in Wanjiaba and Shizhai [M]. Chinese Bronze Drum Research Society. Record of the second colloquium of Chinese Bronze Drum Research Society. Beijing: Cultural Relics Press, 1986: 56-73.

[8] Yunnan Archaeological Team. Report on excavation of ancient tomb in Chuxiong Wanjiaba [J]. Acta Archaeologica Sinica, 1983 (3).

[9] Ditto

[10] Ditto.

[11] Wu Zhao. Detection of pitch of bronze musical instrument of Tomb M1, Luobowan, Gui County, Guangxi and relevant problems [J]. Musicology in China, 1987 (4).

[12] Pang Cuanwu, Li Shihong. Acoustical features of Pubei Sheep Hornbell [J]. Journal of Guangxi University for Nationalities, 1989 (3).

[13] Yuan Huatao. Research on several issues of Sheep Horn-bell [D].Guangxi University for Nationalities, 2007.4, 11-12.

[14] Chief editorial department of Collection of China's music heritage. Collection of China's music heritage (Shaanxi volume) [M]. Zhengzhou Daxiang Press House, 1999:29.

[15] Shaanxi Museum. Group of bronze ware in Qijia Village, Fufeng. [M] Beijing: Cultural Relics Press, 1980: 97

[16] Chief editorial department of Collection of China's music heritage Collection of China's music heritage (He'nan volume) [M]. Zhengzhou: Daxiang Press House, 1996: 86-92.

[17] Chief editorial department of Collection of China's music heritage. Collection of China's music heritage (Beijing volume) [M]. Zhengzhou: Daxiang Press House, 1996:52.

[18] Chief editorial department of Collection of China's music heritage Collection of China's music heritage (Hubei volume) [M]. Zhengzhou: Daxiang Press House, 1996: 202.

[19] Li Chunyi. Unearthed musical instrument of China in ancient times [M]. Beijing: Cultural Relics Press, 1996: 290. 